\title{
CONSIDERAÇÕES E PROPOSTAS PARA A POLÍTICA DE CONSERVAÇÃO DE MATERIAIS PÉTREOS DO PATRIMÔNIO CONSTRUÍDO NO BRASIL
}

\author{
Giovana Maria Nassif Henrique ${ }^{1}$, Antônio Gilberto Costa ${ }^{2}$ \\ 1 - Historiadora. Doutoranda no Programa de Pós-Graduação em Geologia IGC-UFMG; \\ 2 - Professor Titular do Dep. de Geologia e Coordenador do LABTECRochas IGC-UFMG \\ giovana1102@gmail.com
}

Resumo: Este artigo pretende abordar a questão das políticas de conservação no Brasil voltadas para o patrimônio cultural construído, especificamente no tocante aos materiais pétreos. Como forma de preencher estas lacunas identificadas na política nacional, pretende-se recorrer a práticas e metodologias atualmente adotadas no âmbito da política cultural da União Europeia, especificamente em Portugal, visto que nesse país ações implementadas e referentes à problemática da conservação de materiais pétreos no patrimônio construído tem alcançado resultados satisfatórios, podendo, portanto, contribuir e referenciar propostas que se mostrem necessárias e adequadas à realidade do Brasil.

Palavras Chave: patrimônio; rochas; conservação

Abstract: CONSIDERATIONS AND PROPOSALS FOR CONSERVATION POLICY OF STONE MATERIALS FROM HERITAGE BUILT IN BRAZIL. This article aims to deal the issue of conservation policies in Brazil, focused on built cultural heritage, specifically regarding to stone materials, and how such mechanisms have beenseen insufficient and sometimes nonexistent to meet the demands of brazilian material heritage properties. In order to fill these gaps in Brazilian politics, cultural policy adopted in the European Union and Portugal, which actions have obtained a certains successful and, probably, increase appropriate proposals concerned about the context of our country reality.

Keywords: Heritage; Stone; Conservation

\section{INTRODUÇÃO}

Desde os estágios mais primitivos da existência humana, as rochas estão presentes em seu cotidiano. Num primeiro momento, em seu estado natural, a pedra serviu como abrigo; depois, elas foram moldadas como armas, ornamentos, utensílios e como matéria prima para os pigmentos da pictografia rupestre. A partir de então, “(...) seus descendentes não só passaram a compreender sua diversidade (...) como também aprenderam a identificar suas potencialidades, por conta de suas características, e aperfeiçoaram as técnicas para sua extração." 1

Nesse contexto e em tempos mais recentes temse que:

(...) a rocha é o principal material de construção dos monumentos e edifícios históricos (...), não somente pela sua abundância, mas pela sua resistência e durabilidade, visto que suas propriedades físicas e químicas estão diretamente ligadas às suas características intrínsecas, as quais condicionarão os usos mais adequados da rocha no revestimento de edificações, pois o uso adequado do material a ser utilizado possibilita sua maior durabilidade perante as solicitações de uso: intempéries, desgaste abrasivo pelo tráfego de pedestres, danos relacionados às variações térmicas e pela poluição. ${ }^{2}$

Assim, uma das importantes aplicações das rochas, a partir daqui entendidas e referenciadas como materiais geológicos ou pétreos - está

doi: $10.18285 /$ geonomos.v24i2.853 relacionada com a construção de edificações e monumentos, que em parte integram o denominado patrimônio cultural, seja ao nível dos países, seja da humanidade. Nessas circunstâncias e uma vez aplicados em elementos desses patrimônios, esses materiais geológicos passam a fazer parte de um conjunto que envolve inúmeras áreas do conhecimento, tais como: História, Memória, Arquitetura, Patrimônio, Artes e Engenharia.

No Brasil, é de se constatar que, nas últimas décadas, houve um maior aprofundamento no tocante a questões relativas ao Patrimônio Cultural, em especial com relação àquele construído com a utilização de materiais pétreos, que nesse artigo passa a ser identificado como Patrimônio Cultural Construído.

Ainda que alguns considerem a rocha ou a pedra como sendo um material eterno, sabe-se que esses materiais pétreos começam a sofrer alterações desde sua formação no interior da crosta terrestre. Essas alterações seguem atuantes e até se intensificam quando esses materiais são extraídos e aplicados:

(...) a tentativa de adaptação a um meio diferente daquele a que se encontravam sujeitas as suas jazidas. Não é um fenômeno novo, tendo sido evidente para diversos observadores ao longo dos séculos. Referências várias foram efectuadas por escritores gregos e romanos sobre a necessidade de intervenção nos processos de deterioração. Todavia, nas últimas décadas, o processo de decaimento tem-se vindo a acentuar, devido sobretudo à presença na atmosfera de 
concentrações anómalas de diversos tipos de contaminantes. $^{3}$

Assim sendo, atenção deve ser dada com relação às conservações desses materiais nessas construções, mas para tanto profissionais com conhecimentos sobre os mesmos e suas respectivas degradações devem ser envolvidos nos processos de conservação, desempenhado suas atividades em parceria com outros profissionais e em especial com conservadores. Segundo recomendação do ICCROM:

Understanding the material composition, characteristics, and decay mechanisms of heritage objects, as well as the scientific principles underlying conservation materials, methods, and approaches, is crucial for making sound decisions about conservation strategies. $\left(\right.$ ICCROM $\left.^{4}, 2016\right)$

Considerando-se os últimos dez anos, constatase que questões relativas ao patrimônio cultural construído, no Brasil, passaram a ser abordadas, ainda que de modo muito diferenciado, nas pautas institucionais, acadêmicas e legislativas, tanto ao nível estadual, quanto nacional. No entanto, quanto às rochas propriamente ditas, bem como suas aplicações e diferentes demandas nas áreas da conservação ou do restauro, só muito recentemente passaram a fazer parte das preocupações das instituições que cuidam da preservação desse patrimônio. Esses materiais, apesar da diversidade e do volume empregados, ainda são tratados de forma tímida nos projetos de conservação ou restauro ou nas demandas relacionadas com a conservação de bens que integram o conjunto do patrimônio cultural construído do Brasil. Levantamentos realizados confirmam a quase inexistência de políticas ou procedimentos/protocolos com relação ao tratamento de questões envolvendo a pedra nas ações relacionadas com a conservação desse patrimônio cultural construído.

Com o intuito de uma adequada avaliação da situação da conservação de materiais pétreos do patrimônio cultural construído brasileiro, informações sobre políticas ou procedimentos em países com tradição no tratamento dos materiais pétreos, nomeadamente em países da Europa, foram levantadas e pesquisadas. Dentre esses países, mereceu maior atenção a avaliação de procedimentos em Portugal.

A escolha justifica-se, pois além de possuirmos a herança lusitana tanto do estilo, quanto da devoção em expressiva parte do nosso patrimônio construído $^{5}$, Portugal apresenta reconhecida

\footnotetext{
${ }^{3}$ DIONÍ́sIO et al, 2004, p.61.
}

5 - características "transferidas - na pessoa dos antigos mestres e pedreiros "incultos" - para a nossa terra (...) conferiram, (...) à arquitetura portuguesa na colônia esse ar despretensioso e puro que ela soube manter, apesar das vicissitudes porque passou, at meados do século XIX". - como o caso do Barroco Colonial, (COSTA, s/d, p.31). vanguarda em relação ao Brasil no tocante às formações de profissionais especializados, que há muito trabalham de forma interdisciplinar no campo da conservação do seu patrimônio construído, como nos casos mais emblemáticos e envolvendo o Mosteiro dos Jerônimos, em Lisboa e o Santuário de Bom Jesus do Monte, em Braga.

Como elemento indispensável para tal reflexão e consequentes proposições, tomou-se como questão central a ampliação e a valorização da concepção da interdisciplinaridade junto aos processos que envolvem Conservação e Restauro.

No caso deste estudo, considerando as contribuições positivas desse trabalho interdisciplinar no tocante à preservação do patrimônio construído em pedra, procurou-se avaliar, por exemplo, a extensão e o envolvimento de áreas de interesse, como deve ser a da Geologia, que responde pelo conhecimento das características dos materiais pétreos e das suas degradações.

\section{CONSERVAÇÃO DO PATRIMÔNIO CULTURAL CONSTRUÍDO: UMA AÇÃO INTERDISCIPLINAR}

As preocupações iniciais com a preservação do patrimônio cultural construído remontam, de forma mais incisiva, ao século XIX. Desde então, muito tem sido pesquisado e como resultados tem-se a adoção de procedimentos cada vez mais adequados.

Além do fato de as discussões acerca da conservação e do restauro se mostrarem sempre dinâmicas, um aspecto de suma relevância deve ser considerado para que as ações/práticas decorrentes destes processos sejam realizadas o mais adequadamente em relação ao contexto e, sobretudo, ao objeto da intervenção: a interdisciplinaridade como um elemento determinante ao, digamos, "sucesso" das empreitadas relacionadas com a preservação desses patrimônios. Dessa forma, projetos de conservação e de restauro, devem primar por envolver, além do conservador/restaurador, profissionais de diferentes áreas, a saber, arquitetos, historiadores, químicos, geólogos, biólogos e engenheiros.

No caso dos projetos brasileiros envolvendo materiais pétreos aplicados em construções históricas, constata-se uma quase ausência de trabalho interdisciplinar, quer seja na fase de diagnósticos, quer na de implementação de ações de preservação ou restauro. Nesses projetos, onde as rochas constituem os objetos de ações de preservação, a participação, por exemplo, do geólogo, tanto na caracterização dos materiais, quanto na fase do diagnóstico, que deveria ser considerada imprescindível, só muito raramente tem sido observada, apesar de ser este o profissional que detem os conhecimentos necessários para a 
identificação dos materiais e seus processos de degradação. Considerando a necessidade desses conhecimentos para o estabelecimento de diagnósticos corretos, esses devem se mostrar igualmente necessários para as recomendações ou indicações de ações para a conservação ou para o restauro.

No momento, reitera-se que a interdisciplinaridade sugerida só considera o envolvimento de profissionais inseridos e atestados, tanto no meio patrimonial, quanto do mercadológico. Contudo, no sentido de ampliar o raio de ação desta interdisciplinaridade já reconhecida e trazer ao universo da Conservação/Restauro outros técnicos que possam responder com propriedade sobre os materiais pétreos, é que se propõe chamar à ação também o envolvimento, por exemplo, dos geólogos.

É fato, que ainda é reduzido o número de profissionais dessa área envolvidos com o tema e são esparsos os trabalhos geológicos acerca das aplicações desses materiais, mas o desenvolvimento de pesquisas relacionadas a materiais pétreos empregados nas construções históricas do Brasil vem aumentando e contribuindo não só com o levantamento dos tipos desses materiais, mas também com informações sobre as áreas fonte de onde esses foram retirados. Se não é do interesse do geólogo envolver-se com diagnósticos, caberia a ele prover as instituições que cuidam do patrimônio com informações detalhadas sobre as rochas e suas antigas áreas de extração. Algumas dessas informações já se encontram em trabalhos publicados ${ }^{6}$.

Ainda nessa área da geração de conhecimentos, pouco tem sido produzido pelos geólogos, seja com relação à identificação de processos de degradação, seja com relação às suas explicações e posteriores diagnósticos.

$\mathrm{Na}$ direção da identificação de propostas concretas e envolvendo a participação dos geólogos nesses processos, podem ser citados os trabalhos de Bernard Fitzner ${ }^{7}$ e de José Delgado Rodrigues. Dentre os méritos desses trabalhos pode ser mencionada a proposição de metodologias, que se mostram adequadas ao tratamento de rochas aplicadas $^{8}$.

Em especial, a metodologia Proposta por Bernd Fitzner envolve a adoção de ensaios ou avaliações

${ }^{6}$ Como em como em COSTA, 2009.

7 FITZNER, B.\& HEINRICHS, K, 2002 (2002): Damage diagnosis on stone monuments weathering forms, damage categories and damage indices.- In Prikryl, R. \&Viles, H. A. (ed.): Understanding and managing stone decay, Proceeding of the International Conference "Stone weathering and atmospheric pollution network (SWAPNET 2001)", 11-56, Charles University in Prague, The Karolinum Press.

8Desenvolvido pelo grupo de trabalho "Pedras Naturais e Intemperismo", da Aachen Universityof Technology, na Alemanha. não destrutivas (Figura 1). Realizadas in situ, essas avaliações tem início com o levantamento das litologias aplicadas e de suas degradações, que permitem a produção de mapas de litologias e de danos, que por sua vez apontam para a intensidade dos processos que levaram à degradação dos bens estudados, bem como ajudam na formulação de diagnósticos e na recomendação de ações de conservação.

\section{POLÍTICAS PARA A PRESERVAÇÃO DO PATRIMÔNIO CULTURAL CONSTRUÍDO}

\subsection{A Conservação do Patrimônio Cultural Construído no Brasil}

No Brasil, para a conservação do seu patrimônio cultural construído, inexistem por um lado protocolos específicos envolvendo o tratamento dos materiais pétreos, assim como instruções sobre os profissionais que deveriam ser envolvidos nas diferentes etapas relacionadas com os cuidados com esse patrimônio. Trabalhando com a ideia da interdisciplinaridade, caberia a esses profissionais, definir necessidades e tipos de intervenções na conservação ou restauro de bens que compõem esse conjunto do Patrimônio Cultural Construído, como por exemplo, o geólogo.

Assim sendo, verifica-se que, por um lado, as instituições responsáveis pela proteção desse patrimônio, tem se valido sempre de apenas arquitetos, por exemplo. Por outro lado, estes arquitetos acabaram se estabelecendo e, às vezes, atuam de maneira isolada, e não interdisciplinar, na medida em que também não encontram retorno de outras áreas, como, por exemplo, da própria Geologia.

Prova dessa situação pode ser obtida a partir da constatação de busca pelos arquitetos de algum conhecimento na área das pedras, seja por meio da participação em cursos de curta duração, ou da busca de algum conhecimento básico por meio da literatura. Alguns trabalhos realizados por alguns desses profissionais ligados a instituições encarregadas da conservação, resultaram, por exemplo, na elaboração de glossários tratando de definições geológicas, com os quais uns esperam ajudar o trabalho de outros nessas tarefas ligadas à conservação ou ao restauro envolvendo materiais pétreos.

Em suma, a investigação vem revelando, até o momento, que o envolvimento das instituições que respondem pelo patrimônio cultural construído do país sempre tiveram, e ainda continuam tendo os arquitetos, como os únicos técnicos responsáveis pelas demandas concernentes às rochas aplicadas nas edificações e estes, por sua vez, buscaram maneiras de responder minimamente a algumas das 
demandas surgidas, só que isso, por si só, não deve ser considerado suficiente. No caso dos materiais pétreos, por exemplo, caberia ao geólogo responder com propriedade e responsabilidade técnica pelos materiais pétreos envolvidos.

Deve ser destacado que geólogos, por exemplo, quando presentes, são geralmente convocados como "consultores" terceirizados, uma vez que nos editais de licitação para trabalhos de restauração onde está presente a pedra, até agora não foi verificada a exigência de participação dos mesmos.
Quando requisitado, trata-se de uma iniciativa particular da empresa contratada para a realização de procedimentos de manutenção/conservação/restauração de algum monumento. Por outro lado, como essa demanda praticamente inexiste, verifica-se que os cursos ao nível da graduação não preparam os futuros geólogos para esse tipo de envolvimento com a conservação ou o restauro de bens construídos em pedra.
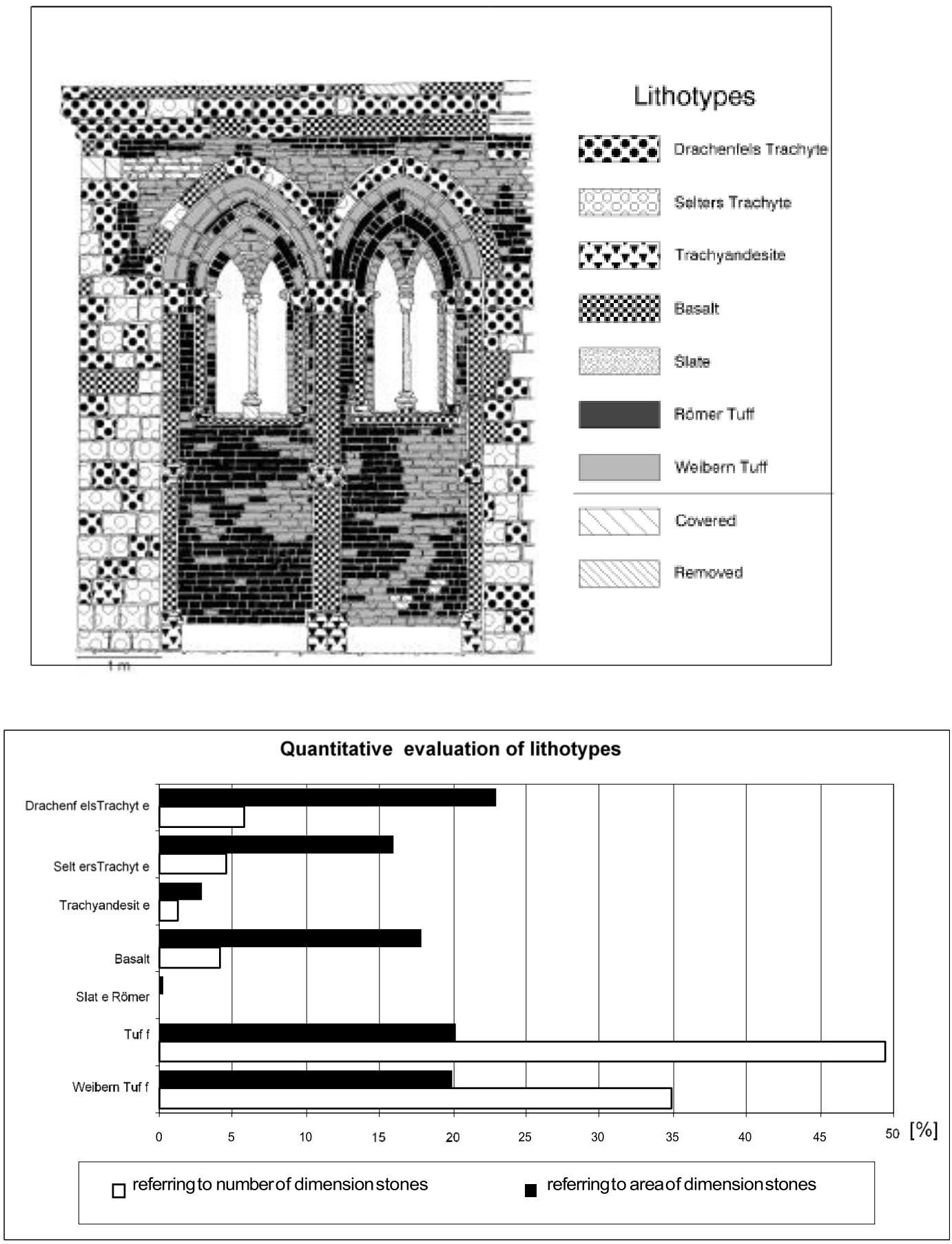

Figura 1. Mapa litológico e evolução quantitativa dos litotipos. Parte da torre da Catedral de St. Quirin, Alemanha. Fonte: FITZNER \& HEINRICHS, 2002. 
Desde quando se deu o que podemos chamar de "início da política de preservação no Brasil" com a instituição do Serviço do Patrimônio Histórico e Artístico Nacional (SPHAN) - criado pela lei no 378, de 13 de janeiro de 1937 e regulamentado pelo decreto-lei $n$ o 25 de 30 de novembro do mesmo ano - muitos sítios, aos quais se atribuiu um valor histórico-arquitetônico, paisagístico e urbanístico, foram submetidos ao processo de Tombamento, por meio do Decreto-Lei $n^{\circ} 25$, de 30 de Novembro de 1937. A esse processo, que passou a se constituir na principal, senão a única figura jurídica (BRASIL, 2010) de proteção ao patrimônio material no Brasil somaram-se as convenções mundiais estabelecidas pela UNESCO, das quais o Brasil é signatário, que foram incorporadas ao ordenamento jurídico brasileiro, por meio de decretos legislativos. Em nenhum momento as questões levantadas mereceram tratamento adequado. Considerando-se outras instituições, vigilantes como o Ministério Público, também é de se constatar que essas questões relacionadas com a conservação de materiais do Patrimônio Construído não são objeto de nenhuma lei, decreto ou mesmo diretriz, denotando que tal temática ainda não é tratada pelo poder público de forma significativa e específica.

Apesar de nas últimas décadas, ter se verificado, na política cultural brasileira:

crescentes esforços no campo, com a produção de numerosos escritos de grande valia, voltados, em sua maioria, para a análise das políticas públicas de preservação, releituras críticas da atuação dos órgãos de preservação, (...) os princípios de preservação (...) - nunca foram incorporados em nossa legislação. Existem algumas indicações nas leis de tombamento, mas que, na verdade, são lacônicas sobre esse problema. (KUHL, nov. 2005/ abr. 2006, p.16-40)

consideram-se como documentos de referência para procedimentos relativos à Conservação do Patrimônio Construído no Brasil as chamadas Cartas Patrimoniais, sobretudo a Carta de Veneza (1964) e a Carta de Burra (1980) e o Manual de Conservação de Cantarias, publicado pelo IPHAN em 2000 (AMORIM, 2014), ainda que o mesmo não se constitua em um documento legitimador ou oficial.

3.2. Políticas culturais européias: referências e contribuições para o Brasil

Nos últimos vinte anos, as políticas culturais européias tornaram-se importantes mecanismos para a recuperação de várias cidades, com fortes contribuições para a economia de diversos países (BIANCHINI, F.; PARKINSON, M, 1993). No tocante às pedras, a excelência dessas políticas culturais da União Européia deve-se, dentre outros fatores, à existência de projetos e de redes, representadas por laboratórios que se dedicam, além da caracterização dos materiais pétreos, também à conservação das mesmas. Desde o início dos anos 90, estes laboratórios, da área de Ciência, Tecnologia e Inovação, reuniram-se nas mencionadas "redes", sob os auspícios da cooperação, da normatização e da interdisciplinaridade - que conta com a participação de inúmeros profissionais de áreas afins, incluindo os geólogos.

Nessa área e como estado-membro da UE desde 1986 (UNIÃO EUROPEIA, 2015), Portugal tem sido considerado como um caso excepcional, mesmo a despeito dos efeitos provocados por uma "certa carência de capital" (MAGALHÃES, 2014). Esse país possui instituições e profissionais mundialmente reconhecidos por seus trabalhos e suas publicações, além da existência de laboratórios voltados à conservação da pedra, como o LNEC (Laboratório Nacional de Engenharia Civil), o CEVALOR (Centro Tecnológico da Pedra Natural de Portugal), o CEPGIST (Centro de Petrologia e Geoquímica), o LNEG (Laboratório Nacional de Engenharia e Geologia) e o Laboratório Hércules.

Tais avanços suscitaram a necessária inclusão das rochas nas pautas de conservação do patrimônio construído, bem como uma maior valorização da interdisciplinaridade, possibilitando o envolvimento de profissionais diversos - incluindo geólogos. Apesar de dificuldades enfrentadas, o exemplo lusitano de conservação dos materiais pétreos no patrimônio construído pode contribuir, de forma significativa a proposições e adequações à realidade brasileira, ainda que sejam contextos diversos.

\section{CONSIDERAÇÕES FINAIS}

Essa lacuna verificada na política cultural brasileira referente ao tratamento dos materiais pétreos confirma a necessidade para a elaboração de medidas protetivas legais, cujo objeto refira-se à conservação dos materiais pétreos no patrimônio construído. Os processos de alteração/deterioração das rochas são inexoráveis e demandam tratamentos adequados e a adoção de medidas até aqui muito incipientes ou ausentes no Brasil.

O modelo aplicado na União Européia/Portugal revela contribuições valiosas no tocante a instrumentos de pesquisa e execução de trabalhos relativos à conservação dos materiais pétreos, que se baseia na formação de pessoal e na implantação de redes de laboratórios, com pessoal qualificado e com formação interdisciplinar, assim como infraestrutura adequada e financiamentos.

No Brasil, até o presente momento, não se tem notícia ou informação a respeito da existência de um padrão como o da Europa/Portugal focada nas questões que envolvem o patrimônio construído. As iniciativas ainda são isoladas e insuficientes e na 
maior parte não contemplam as pedras. No momento, laboratórios exercem função de consultores terceirizados, contratados pelos órgãos públicos como IPHAN e/ou IEPHA (que também aprovam e fiscalizam) para execução de projetos envolvendo o patrimônio construído. Contudo, esses projetos por não contarem com equipes envolvendo profissionais com formações nas áreas de interesse, acabam por promoverem intervenções inadequadas com danos irreversíveis para o patrimônio.

Isto posto, cabem questões tais como: como regulamentar, na ausência de uma legislação específica, e como mitigar os efeitos de intervenções inapropriadas às demandas do patrimônio?

Não se mostra imperativo que geólogos, por exemplo, estejam presentes em equipes de instituições envolvidas com a preservação do patrimônio, como por exemplo do IPHAN, mas deve ser considerado imperativo ter a sua experiência, ainda que de forma terceirizada, mas exigida, para o levantamento de diagnósticos e proposição de ações a serem colocadas em prática pelos conservadores. Outra prática recomendada, em especial a partir de experiências européias, tem a ver com o incentivo para a formação de redes de laboratórios especializados e de parcerias com as instituições responsáveis pela pesquisa e pela formação de profissionais nas áreas de interesse para a conservação e restauro de materiais pétreos.

\section{REFERÊNCIAS BIBLIOGRÁFICAS}

AMORIM, J.M.C. Entrevista em 28 de fevereiro de 2015. IPHAN Santa Catarina $/ 11^{\mathrm{a}}$ Superintendência.

BIANCHINI, F.; PARKINSON, M. Cultural Policy and Urban Regeneration: The West European Experience. Manchester University Press, 1993.)

BRACARA AUGUSTA. Revista Cultural de Regionalismo e História da Câmara Municipal de Braga. Braga: Câmara Municipal de Braga/Arquivo Municipal, vol. LIX, n 117(130), 2014, 294 p.

BRASIL. Câmara dos Deputados. Legislação sobre patrimônio cultural. - Brasília: Câmara dos Deputados, Edições Câmara, 2010. 366 p. - (Série Legislação; n. 41).

COSTA, A.G. Rochas e Histórias do Patrimônio Cultural do Brasil e de Minas. Rio de Janeiro: Bem-Te-Vi, 2009, 291 p.

COSTA, L. Documentação Necessária. Revista do Serviço do Patrimônio Histórico e Artístico Nacional, Ministério da Educação e Saúde, 1:31-39. Rio de Janeiro.
DIONÍSIO, A., AIRES BARROS, L. \& BASTOS. A degradação das rochas do património cultural construído - o caso das rochas carbonatadas. Quimica. Boletim da Sociedade Portuguesa de Quimica. Sociedade Portuguesa de Química -SPQ. Abril-junho 2004, Serie II, nº 93 ).

DIRETORIA GERAL DO PATRIMÓNIO CULTURAL - DGPC Santuário de Bom Jesus do Monte. República de Portugal/Cultura; Disponível em: http://www.patrimoniocultural.pt/pt/patrimonio/patrimonio -imovel/pesquisa-do-patrimonio/classificado-ou-em-vias-declassificacao/geral/view/73927/

FITZNER, B.\& HEINRICHS, K, 2002 (2002): Damage diagnosis on stone monuments - weathering forms, damage categories and damage indices.- In Prikryl, R. \& Viles, H. A. (ed.): Understanding and managing stone decay, Proceeding of the International Conference "Stone weathering and atmospheric pollution network (SWAPNET 2001)", 11-56, Charles University in Prague, The Karolinum Press.

ICCROM. International Course on Stone Conservation. Materials and Technology Disponível em: (SChttp://www.iccrom.org/priority-areas/material-science. Acesso em março/2015.

IPHAN - Instituto do Patrimônio Histórico e Artístico Nacional. Livro das Belas Artes (s/d). Arquivo Noronha Santos. Patrimônio Material. Bens Tombados. Disponível em: http://www.iphan.gov.br/ans/inicial.htm. (Acesso em 201412-11)

KUHL, B. M. História e Ética na Conservação e na Restauração de Monumentos Históricos. Revista CPC, São Paulo, v.1, n.1, p. 16-40, nov. 2005/ abr. 2006 )

MAGALHÃES, F. Regionalism in Portugal: How cultural heritage makes a difference in the global context. PortugueseJournalof Social Science. 2014, Volume 13, Number 1.

MASSARA, M. F. Santuário do Bom Jesus do Monte - Fenómeno Tardo Barroco em Portugal. Braga: Confraria do Bom Jesus do Monte, 1988.

MIRANDA, M. P. de S. Tutela do Patrimônio Cultural Brasileiro: doutrina, jurisprudência, legislação. Belo Horizonte: Del Rey, 2006.

UNIÃO EUROPEIA. Estados-membros da EU (ano de adesão). Como funciona a EU. Países. http://europa.eu/abouteu/countries/index_pt.htm. (acesso em 2015-outubro-08).

Contribuição ao

1‥ Simpósio Brasileiro de Caracterização e Conservação da Pedra 14 a 16 de dezembro de 2016, Congonhas - MG

Nota:

É de responsabilidade da comissão editorial do Simpósio a revisão gramatical, ortográfica, de citações e referências bibliográficas. As normas de submissão podem se diferenciar das desta revista. 